\title{
GÉNEROS A MEDIAS: LECTURA FOLCLÓRICA, INFANTIL Y PSICOANALÍTICA DEL CUENTO TRADICIONAL"EL MEDIO POLLITO", EN VERSIÓN DE CARMEN LAFORET
}

\author{
Alexia Dotras Bravo \\ Instituto Politécnico de Bragança \\ Centro de Literatura Portuguesa
}

Title: Half genres: folk, children's and psychoanalytic of the traditional story "El medio pollito", in Carmen Laforet's version

\begin{abstract}
The publisher Cálamo believed the collection "Ilustrados Cálamo" in 20 I 2 to be a good idea, bringing to light the unpublished version of Carmen Laforet about an anonymous story widely disseminated in Spain and Latin America. This version of Laforet, made on a trip to the United States, was written in a single day, probably making more use of the oral, popular memory of childhood remembrances than of his own creative art. The final study in the form of an epilogue by Roberta Johnson and her relations with the lacanian psychoanalytic analysis is of remarkable interest. I propose to compare the version of Carmen Laforet with other known versions of authors, both Spanish and Hispanic American, from the perspective of literary structure, fidelity to folk traits and psychoanalytic Reading.
\end{abstract}

Key words: Carmen Laforet. El medio pollito. Popular Literature. Version. Psychoanalytic reading.

\section{INTRODUCCIÓN: DE LA AUTORA Y DE LOS ORÍGENES DEL TEXTO} TRADICIONAL

Carmen Laforet (192 I-2004) es una de las voces hispanas más reconocidas del siglo XX. Mitificada en ese mismo prestigio, misteriosa por su relación autobiográfica con su obra, su vida privada, sus relaciones artísticas (incluso reseñadas en vida de la autora, Palomo: 1958, y que hoy la crítica sigue resaltando, Ripoll: 2016). Por ello quizás hemos tardado algún tiempo en conocer este El medio pollito, texto inédito hasta la fecha que nos permite contemplar el manuscrito autógrafo de la autora del i6 de octubre de i 988 , como afirma Roberta Johnson en el epílogo, una de las grandes estudiosas de Laforet (Johnson: i 979, Johnson: 2005).

La historia de El medio pollito, si tenemos en cuenta la nota introductoria de la autora, es un texto antiguo, anónimo -o impersonal- de tipo popular, que mantiene todas las características que conocemos desde 
el comienzo de los estudios folcloristas, no solo hispánicos (Propp: 1928 [1 1977], Chevalier: 1995 y 1997, Redondo: 2007, Espinosa: 1946- 1947 [2009], Pisanty: 1995, Pelegrín: 2004, Morote: 2002, Rodríguez Almodóvar: 1993 y 2003), así como gracias a algunos volúmenes ya paradigmáticos (García de Enterría, 1995). A pesar de ser un cuento muy conocido, se ofrece una sinopsis del mismo. Se trata de un medio pollo, que vive en un mundo de medio sujetos, el cual emprende un viaje para recuperar una moneda que presta al rey. En el viaje conoce a varios medios sujetos que va metiendo en su ano, de una forma disparatada y escatológica, propia de los cuentos populares. En su lucha contra el malvado, malhumorado y avaricioso rey, que no le quiere devolver el dinero y encarga a la criada que lo mate sucesivas veces, va llamándolos ante a medida que los necesita y le ayudan a conseguir su objetivo y restablecer el orden perdido.

Estos cuentos se identifican gracias a una serie de rasgos clave como son la oralidad (de la que se desprende la repetición para favorecer la memorización), el anonimato (o impersonalidad, término más exacto), la transformabilidad, la brevedad, la sencillez y la filiación del emisor y del receptor como procedentes de la misma clase social. Pero, sobre todo, se identifican por su origen secular, su pervivencia a lo largo de los siglos. Su longevidad asegura una mayor aproximación a las estructuras esquemáticas propias de los cuentos infantiles tradicionales de "supuesto" origen oral. El género 'cuento' se caracteriza por una estructura esquemática particular que se define como el conjunto de "partes o elementos estructurales de comienzo, desarrollo y conclusión que se realizan a través de unos patrones o pautas (realization patterns), que son las opciones léxico-semánticas que caracterizan un texto y que nos ayudan a reconocer su género", como afirman Moya y Albentosa (2007: 232). La división de los cuentos tradicionales es la clásica tripartita con presentación, nudo o desarrollo y desenlace, que tiende a dividirse en el interior del nudo debido a la similitud de acción -representada 
por un esquema sintáctico reiterado- en dos, tres, siete o cualquiera de los números habituales, números mágicos, propios de la literatura de hadas (Lorenzo Vélez, I 98 I; Del Bosque, I 998).

Será uno de estos estudiosos, Rodríguez Almodóvar, quien nos ofrezca información y versión de El medio pollito: es un cuento de cuentos, "un texto representativo de muchos textos" (I993: 9) ya que lo cita en sus ejemplos del arquetipo como un cuento riquísimo en interpretaciones simbólicas (1993: 18) y lo había incluido en su colección de Cuentos de la media lunita ( 1985 ) con el título de El medio pollito y el medio real, solo tres años ante de esta versión escrita por Laforet en el viaje a Estados Unidos.

Este arquetipo, tal y como explica Rodríguez Almodóvar, podría nacer de los primitivos actos de habla creativa, si así podemos llamar al cuento maravilloso indoeuropeo, que se retrotrae al "bajo Neolítico, al transformarse las sociedades de cazadores-recolectores en sociedades agrarias, nucleadas en torno a los nuevos valores de la propiedad privada, la herencia y la familia exógama" (1993: I I). Esos cuentos son expresiones de rituales antiguos, de iniciación, de prohibiciones expresas, de maduración... Por ello han resultado tan atrayentes a psicólogos y antropólogos: por ser relatos cifrados, crípticos.

Es decir, El medio pollito es un cuento del que existen versiones - la de Laforet es una de ellas-o prototipos que, al juntar los rasgos comunes de estas versiones, proporcionaría el arquetipo, idea que aquí no contemplamos, ya que claramente la versión de Laforet, versión culta de autora, es bastante libre en el comienzo y en el desenlace, lo que indica cambios sustanciales en los objetivos. Pretendemos leer esta versión cristalizada por Laforet desde perspectivas psicoanalíticas de género, especialmente Lacan, ya que Johnson lo cita como autoridad que legitima al personaje del medio pollito como un alter ego de cualquier sujeto, siendo este medio sujeto, y poniéndolo en relación con otras versiones de la LIJ, de autores españoles y 
latinoamericanos, que también se apropiaron del arquetipo para recrear su propio prototipo ya culto y contemporáneo.

2. De los Rasgos Folclóricos de "El medio pollito" De LafoRET A OTRAS VERSIONES INFANTILES MODERNAS

Antes de entrar en la lectura de género, debemos pararnos en los rasgos fundamentales de la literatura tradicional o folclórica que florecen en $E l$ medio pollito. Ello también es importante porque los personajes, la estructura, las funciones y la trama son de tipo primitivo y sirven para explicar algunos estados, formas o rasgos de la psique. Los primeros elementos que saltan a la vista son la repetición (“AAdónde vas, medio pollito?”, "Pues anda lo que yo ande” / “Señor rey, señor rey!”, “¿Qué pasa, condenada mujer?”), tan atractiva al público en su dramatización, ya sea iletrado o infantil, para poder empatizar y cantar/recitar/representar a coro. Hay también algunas marcas clásicas de oralidad y de actualización en la puesta en escena oral del cuento, tales como la idea de paso del tiempo a través del gerundio ("Siguió andando, andando", "siguió y siguió andando") o la muestra gestual para presentar intensificadamente en cada actualización del cuento ("acertó a pasar por allí el rey que era así”). Otro elemento fundamental es el diminutivo, la sensación de pequeñez que provoca ternura, en todos los cuentos tradicionales, pero especialmente en este, donde la ausencia de plenitud del sujeto es la esencia de la identidad y del género. Si todos los textos populares demuestran unas implicaciones lingüísticas similares al discurso oral, ello conduce directamente a un registro en un contexto, en una situación concreta esencialmente coloquial, sencilla y con escasa autorreflexión o corrección derivada de ella. Sin embargo, por el simple hecho de cristalizarse por escrito en un momento histórico determinado "el cuento queda domesticado porque toda escritura es racionalización, la sintaxis exige carriles más rígidos que la palabra dicha, que es sugerente, enriquecida por el gesto, las curvas de entonación, la circunstancia social" (Tamés, 1990: 2 I-2 I). 
Para observar los rasgos folclóricos es necesario realizar una breve cala en las versiones más conocidas del cuento, enumeradas y analizadas por Roberta Johnson, y en otras que hemos encontrado y que inciden en unos $\mathrm{u}$ otros elementos del folclore más primigenio. En cualquier caso, todos ellos, tal como Laforet, se empapan del acervo popular del cuento porque:

Tenemos testimonios de escritores famosos que guardan en su prodigiosa memoria la huella que ha dejado en ellos su contacto infantil con los cuentos, por los que han caminado, de los que han aprendido y que han incorporado a sus creaciones posteriores, en una permanente fusión entre lo tradicional, cuya característica esencial es la oralidad, y la modernidad, cuya base se asienta en la escritura creada a partir de las palabras recibidas y asimiladas con el paso del tiempo (Morote, 2002: I 59).

La primera referencia que Johnson realiza se debe a los Cuentos populares de España (1923) de Aurelio M. Espinosa, con una segunda versión de 1946 con el título Colección de cuentos, especificando que es de Cuenca, justificándolo con el diminutivo en -ico. Sin embargo, Agustín Redondo le otorga el origen aragonés (2007: 136) a través de Arcadio Larrea, que en I 947 divulgó el tal cuento y se recogió de nuevo en 2000. Sea de Castilla o de Aragón, el sufijo - ico se encuentra vivo en ambas zonas y también se había manifestado en Asturias y Francia, tradición de la que bebe Lacan y que Larrea documenta en sus notas a pie de página (2000: 29). Es estos dos casos cambia sustancialmente la trama, ya que la autoridad del rey en Laforet se transforma en el típico molinero ladrón, personaje malvado que "aparece con frecuencia en el folklore europeo” (Redondo, 2007: I 35). Roberta Johnson le supone un origen antiguo, incluso oriental porque presenta reminiscencias de la historia del rey Salomón en casi todas sus versiones (Johnson, 20 I 2, 49: 53). La historia de Espinosa y la de Larrea acaban de forma trágica, con la muerte del pollito, en el lado diametralmente opuesto a la de Laforet. Sin embargo, el inicio de la obra es prácticamente igual en Laforet y Larrea, es decir, in media res e incidiendo directamente en la acción. 
Una de las versiones más antiguas aparecida en la literatura culta procede de Fernán Caballero, conocida folclorista con sus Cuentos de encantamiento, que la incluyó en La Gaviota (1 849). Es completamente diferente: un pollito soberbio, despreciativo y claramente lleno de taras físicas que él no ve, a pesar de la protección de su madre. En este caso existe una moraleja final, sin rasgos de pulsiones inconscientes o luchas comportamentales, aunque los personajes adversarios sean tres de los cuatro elementos de la tierra -agua, fuego y viento.

La lección moral del cuento queda clara; no se debe ignorar los consejos de los mayores ni buscar unas ilusorias circunstancias supuestamente más favorables por creerse uno superior a los que le rodean (Johnson, 2012: 55)

Faltan otras versiones que no cita Johnson. Tal es el caso de la de Rodríguez Almodóvar, aparecida en la colección de los Cuentos de la media lunita en los años 8o. En este caso nos encontramos con un título algo diferente, ya mencionado: "El medio pollito y el medio real". Como en todos los relatos de Almodóvar, no existe ningún interés por añadidos moralistas, sino que pretende una vuelta al origen del cuento tradicional, al ser el eje de la construcción del yo, los otros y el mundo (Almodóvar, 2003: 3). La literatura popular transmite mensajes profundos (delectare et prodesse horaciano) que, en el caso de El medio pollito sería "la necesidad de ser solidarios" (Almodóvar, 2003: 4).

Además, existen al menos tres versiones latinoamericanas que refiere Johnson (Rosario Ferré, 1978/ 1996, Rafael Jijena Sánchez, 2003 y una versión chilena popular, coordinada por Micaela Navarrete, 2000), con elementos originarios del arquetipo primitivo, pero también incrustaciones morales y sociales. La primera, la de Ferré, es probablemente la más divulgada hoy en ámbito hispánico, como muestra su aparición sistemática en Internet. La autora puertorriqueña, además, es una de las grandes voces poéticas hispánicas. Su versión más moderna no conserva ningún rasgo literario po- 
pular, excepto algo similar a la repetición, pero sin la rigidez de la literatura folclórica, que sí tenía en su primera versión de i978, porque estaba “enmarcada con clásicas frases del cuento tradicional, que vimos en la versión oral, recogida por Espinosa” (Johnson, 20 2: 57). Por otro lado, sí que las dos que restan presentan una raíz folclórica, ya que la de Jijena Sánchez y la popular chilena hacen hincapié en lo verdaderamente social, en la lucha social propia de los cuentos populares, donde el campesino afianza su poder frente a la autoridad a través del ingenio, la magia o la fuerza del equipo. Todos estos elementos, no por acaso infantiles, refuerzan el mensaje social revolucionario que tan bien cala en América Latina. De hecho, Rafael Jijena es un reconocido folclorista argentino que recopila cuentos populares en 1946, fecha coincidente con el segundo volumen de Espinosa, bajo el título de Cuentos de mama vieja (Pulfer, I 946), donde aparece "El medio pollo".

Podemos observar que la clave de las diferencias estriba en los inicios y los finales y en el mayor o menor grado de folclorismo de los cuentos mencionados hasta aquí. Sean o no fuente inspiradora para Carmen Laforet, muestran una base común universal a todas las versiones y, a la vez, un sabor localista y exclusivo en cada uno de los autores:

Los humanos somos seres que no sólo viajamos en el espacio y en el tiempo, sino también -y sobre todo- en la cultura, en las culturas, de cultura a cultura. Vamos por el mundo cargados de nuestra tradición cultural que, a menudo, procede de otros lugares, distantes de aquellos en que estamos viviendo o en donde nacimos. Siempre estamos en tránsito, por lo menos, de una cultura a otra: desde la que llevamos puesta y nos acompaña a otros mundos porque nuestros padres o abuelos nos vistieron con ella, hasta la que contribuimos a crear allí donde nos posamos y que nuestros hijos heredarán (Díaz Viana-Asensio Llamas, 2009: i7-1 8)

En cualquier caso, casi todo lo que rodea a El medio pollito se remonta a América, de donde proceden Espinosa, Ferré, Jijena Sánchez y algunas versiones sin autor, en clara hegemonía sobre las procedencias peninsulares de Larrea, Rodríguez Almodóvar o la propia Laforet que, paradójicamente, lo vuelve a llevar al otro lado del Atlántico, donde lo escribe y lo regala. 


\section{El MEDIO POLLito DE LAFORET Y EL PSICOANÁlisis}

Para realizar un análisis de la historia del pollito en la versión laforetiana, de forma ordenada, comenzaremos en el inicio. La idea principal del nacimiento del pollito a partir de un medio huevo y la pobreza extrema de su dueño, propia del cuento conocido en su versión francesa por Jacques Lacan, ${ }^{\mathrm{I}}$ se eclipsa en la interpretación laforetiana. No interesa la solidaridad ni la compasión o empatía por parte del oyente analfabeto medieval o del niño con el imaginario por construir, sino que incide en la idea de género extraño, diferente desde el inicio. El país, sin nombrar, es de población heterogénea porque en sus variados vecinos los "animales y hombres (...) eran pequeños y les llamaban medio hombres o medio animales" (p. I). Es decir, no se da la idea de mitad de sujeto, sino de sujeto pequeño, insignificante, párvulo. Reproduce, entonces, la idea lacaniana del medio sujeto, expuesta en el seminario XVII, impartido entre diciembre de r 969 a junio de 1970.

El sujeto busca una pérdida, carencia, ausencia, porque es imperfecto y por ello está en la búsqueda del saber. Puede encontrarlo en el erotismo, elemento bastante freudiano, o incluso en el dinero, como en el cuento en causa. A través de ese saber quiere conocer la verdad, pero ambos, verdad y saber, poseen la misma característica: solo se puede adquirir a medias. Esa idea de ser incompleto gobierna todo el seminario XVII sobre "El reverso del psicoanálisis", pero especialmente la IV clase, que atiende a la "Verdad, hermana del goce”, donde aparece la mención del cuento de El medio pollo, primera lectura de su infancia y que determinó el desarrollo de su pensamiento, según las palabras del propio Lacan (2008: 59). Por ser la única

${ }^{\mathrm{I}}$ En la Red circula una versión española de un cuento sobre un medio pollo, que se supone la lectura realizada por Lacan, a pesar de que en su obra publicada sobre el Seminario 17 solo hay una referencia al cuento y no el cuento en sí mismo. Esta versión se puede consultar en varias webs, de la que destaco, a modo de ejemplo: http://www.scbicf.net/nodus/contingut/article.php? $\mathrm{art}=\mathrm{I} 84 \mathrm{rev}=27 \mathrm{pub}=\mathrm{I}$. Este texto es especialmente reiterativo, disparatado y escatológico, con todo el sabor de los cuentos populares. 
mención, es importante ir al texto y comprobar la relación del cuento popular con la lectura psicoanalítica:

Lo que yo enseño desde que articulo algo del psicoanálisis podría muy bien llamarse Historia de medio sujeto. ¿Dónde está la verdadera relación de esta historia de medio pollo con la historia de medio sujeto? Podría tomarse de dos maneras. Puede decirse que la historia de mi primera lectura determinó el desarrollo de mi pensamiento, como diría una tesis universitaria. O bien, punto de vista de la estructura, la historia del medio pollo podía representar, para el autor que la había escrito, algo que reflejaba no sé qué presentimiento, no del sychanalisse como dice Le paysan de París, sino del sujeto. Lo que es seguro es que había también una imagen. La imagen del medio pollo estaba de perfil, por el lado bueno. El otro no se veía, el corte, donde probablemente estaba la verdad, ya que en la página de la derecha se veía la mitad sin corazón, pero sin duda no sin entrañas, en los dos sentidos de la palabra. ¿Qué significa esto? Que la verdad está escondida, pero tal vez no esté ausente.

Como la esencia del psicoanálisis es la palabra y lo que se comunica a través de ella, los principales conceptos que maneja Lacan son el discurso, el enunciado y la enunciación. De hecho, en este seminario es donde ofrece la teoría de los cuatros discursos y patentiza la importancia del lenguaje en el paciente -y en el analista- aunque el lenguaje también deja palmario los límites en el mundo del discurso. Retoma las teorías freudianas sobre el principio de placer, importantes para la lectura escatológica del "culito" del medio pollo como lugar seguro para guardar a sus compañeros de viaje, pero también para ocultar y crear misterio.

Este relato, en la clasificación habitual de los cuentos de hadas según Rodríguez Almodóvar, pertenece a la categoría de “animales”, que son los metafóricos, de ahí la complejidad simbólica en su interpretación psicoanalítica. Las palabras del folclorista nos sirven aquí para dar forma a esta idea:

... la distribución en tres grupos: los maravillosos, los de costumbres y los de animales, es decir, fantásticos, realistas y metafóricos -adelantándose así en unos cuantos siglos y hasta milenios- al modelo de triple relación con 
que hoy trabajan las últimas tendencias del psicoanálisis, entre lo simbólico, lo real y lo representativo. (Desde Freud a Lacan, la relación entre los cuentos maravillosos y la interpretación de los sueños ocupa una parte muy importante de esta teoría). (2003: 5).

Una de las características propias de la LIJ es el uso de diminutivo y la temática desgraciada, con personajes dignos de compasión y de pena. De ahí la sensación de pequeñez sumada al concepto en sí de "medio pollito". Este encuentra su "medio durito" escarbando en un "montoncito" de algo tan desagradable como la basura. Es cierto que de aquí se infiere la presencia de la pobreza, mucho más evidente en las versiones latinoamericanas y en la versión francesa supuestamente leída por Lacan y reproducida en muchos sitios web de psicoanálisis, como ya he mencionado.

El medio pollito, medio sujeto, desgraciado, pequeño, insignificante, debe hacer frente a una petición de la autoridad, del rey - el Amo, en palabras de Lacan- que, curiosamente, no es medio, sino entero, el cual realiza un acto insólito: pedir prestado dinero. Vemos aquí otra de las características fundamentales de la LIJ: el sinsentido, término usado en la misma lección de Lacan en oposición al sentido que otorga "ser" al ser, sin embargo "desde hace cierto tiempo, se vio que esto no llegaba a dar el peso de la existencia, precisamente" (2008: 60), mientras que el sinsentido sí se lo otorga, según el psicoanalista. El sinsentido se remonta a la literatura medieval inglesa, al nonsense, tal y como Bettina Hurlimann lo explicara hace décadas (i 968, en su versión española), sin que pierda fuerza en la posmodernidad literaria actual, desde Alicia en el país de las maravillas ( 1865 ) de Lewis Carrol hasta algunos productos literarios del disparate típicamente hispánicos. En el contexto español no podemos olvidar las retahílas tradicionales del juego que incluye en el canon de LIJ Ana Pelegrín a lo largo de su obra (1984, i 986, 1993), la jitanjáfora - no solo relacionada con la más primitiva expresión popular poética, sino también con las vanguardias de principios de siglo, especialmente el surrealismo y el dadaísmo-, y el disparate y surrealismo de la 
literatura latinoamericana de la que se apropian los niños. Junto con otras, el sinsentido es una de las estrategias subversivas de la LIJ posmoderna que, aunque parezca imposible, muestra "un patrón regulado" (Guerrero Guadarrama, 20 I3: I I7) una lógica dentro del disparate, una lógica infantil, pero también una lógica adulta de las tonterías sin pies ni cabeza.

Como es propio en los cuentos tradicionales existe una clara jerarquía en sus personajes que, en los años ochenta, por parte de los historicistas, se entendía como una rémora del poder social de clases y el mantenimiento de un estatuto social clasista (Cervera Borràs, 1986). Se vinculaba entonces de una manera más positiva al psicoanálisis, gracias al paradigmático Psicoanálisis en los cuentos de hadas (1 976, I 978 en español) de Bruno Bettelheim por varios aspectos, pero el más notable es la lucha por la vida, la superación de los obstáculos, y la asimilación del mal como un aspecto habitual en la existencia. De hecho, Bettelheim bosqueja cómo los cuentos maravillosos plantean los problemas existenciales que debe enfrentar el niño y la ayuda que aquellos brindan a estos. De todas formas, Freud ya había vinculado cuentos de hadas y mitos con el psicoanálisis, "dado que el cuento y el mito repercuten, hacen huella y marcas en la subjetividad, por lo que no resulta del todo extraño encontrarse con algunos de sus elementos en el transcurso de un proceso de análisis" (Rojas Navarro, s. d.: 2). El aliciente para el medio pollito al ceder el préstamo es poder ver el gran palacio, algo que le estaría prohibido por clase social y que, por tanto, estimula su interés. A pesar de ser el rey una autoridad incontestable, quien encara la relación con el pollito laforetiano y abusa de su poder, el personaje medio sujeto no se arredra y manifiesta ostensibles elementos positivos, tanto en su personalidad como en su relación social en la búsqueda de compañeros de viaje para recuperar lo que es suyo. Según Lacan en el seminario citado, en la vida como que en el cuento de El medio pollo lo que se pretendía era representar lo que hay en el sujeto, lo que vemos, lo que en otras metáforas psicoanalíticas se reprodu- 
ce como la punta del iceberg. El autor, anónimo, sabemos que no hablaba en su nombre, sino en el del colectivo, ya que es un representante de su gremio, de su clase, de su ideología y no siente la necesidad personalísima de atribuirse su obra. El perfil del medio pollito enseñaba su lado bueno. Era su mitad capaz, resolutiva, asertiva. La mitad que no se ve, que ya no posee (pero sí fue suya), que perdió, significa que guarda la verdad que está escondida. Afirma que el sentido concierne al significante (el sujeto), no al objeto. De alguna forma, trasparece el concepto de perspectiva o punto de vista, que llega hasta la verdad subjetiva de Hegel, teniendo en cuenta los diversos tipos de verdad kantiana y los límites de lo cognoscible por parte de los seres humanos. Como para Lacan somos seres imperfectos, incompletos, esta verdad oculta, oscura, no puede ser capturada. En sus ausencias, el sujeto nota también la ausencia de verdad. Aquí Lacan explica el concepto del no sentido, del sinsentido, o como se dice en su traducción al español, "sin pies ni cabeza”. He aquí el ciclo que une los elementos de manera armónica: el sinsentido del medio sujeto y el sinsentido surrealista de la literatura infantil, especialmente la de corte clásico. Se trata de una vuelta a las sensaciones primarias, a las primigenias reacciones psicológicas. Es de resaltar que para Freud lo real era el sinsentido, mientras que lo imaginario era lo que dotaba de sentido, siendo lo simbólico lo que confería el doble sentido (Coutinho Jorge, 20 I I). Sin embargo, Lacan, en el contexto del medio pollo o medio sujeto, emplea connotaciones más cercanas a las usadas en la actualidad.

Uno de los elementos infantiles que reseñamos previamente, el motivo del viaje y su compañía, habitual en los cuentos acumulativos, adquiere en este un sentido también pscioanalítico. Para poder continuar el viaje con sus compañeros, casi siempre medios sujetos también han de "andar lo que el pollito ande”. Sin embargo, todos, a pesar de la capacidad física atribuida (lobo, zorro), se revelan ineptos para seguir adelante y la solución del pollito pasa por "meterlos en su culito y cerrar con un palito". El viaje, con 
tantos elementos en el ano y cerrados con un palito, le confiere no solo un poder especial, sino que también nos traslada a la teoría freudiana de las fases infantiles del desarrollo psicosexual, la segunda de las cuales es la anal. Las identifica con dos caracteres diferenciados: la retención anal muestra un individuo organizado, pulcro, mientras que la expulsividad anal es propia de sujetos más imprudentes, rebeldes o desorganizados.

En el cuento de Laforet el pollito retiene y acumula mientras está en la búsqueda del objetivo último, es decir, llegar al gran palacio para recuperar su medio durito. Una vez que llega al gran palacio y el objeto de su viaje le es denegado, debe expulsar cada uno de los medio sujetos que le ha acompañado para que contribuyan a su éxito. No implica especialmente desorganización o caos, pero sí una tensión extrema, porque sin la ayuda de los acompañantes sería imposible la consecución del éxito. Cada expulsión es una liberación y una batalla ganada. En este sentido, el cuento recuerda a otros textos populares con pulsión anal de cariz intencionalmente cómico, tal como El rey y la piel del piojo y El tragaldabas, otros cuentos tradicionales de corte escatológico -en el primero uno de los personajes es llamado a través del atributo que lo hiperparticulariza "sopla-con-el-trasero"- en el que la colaboración es imprescindible para la adquisición del objeto deseado. Pero existe una razón por la que el texto de Laforet es más oral, coloquial, espontáneo y que se vincula directamente con el final del cuento: el uso del término vulgar "culo". Es evidente que el uso de la palabra "culo" va a resultar deliciosamente divertida a los más pequeños, haciendo hincapié además en el sentido que adquiere el texto y la superación del obstáculo, tal y como sucede con el Tragaldabas que no se mete por el ano a los personajes, sino que los ingiere por la boca para sí expulsarlos por el culo de una forma disparatada y muy cómica.

Con todo, resulta extraño la falta de consistencia en la versión de Laforet, ya que los únicos seres humanos no son medio sujeto, a pesar de la 
afirmación inicial de que les llamaban "medio animales". Los arrieros son completos y sus burros también. Se hacen pequeños, sí, pero no suponen una pequeñez de un medio sujeto, o sea, una doble carencia o defecto. El medio zorrito y el medio lobito se hacen más pequeños todavía implicando una fragilidad notoria que no se percibe en los arrieros, o incluso en el río, el único elemento no animado dentro de la trama de la historia.

También resulta chocante que en el gran palacio del rey (no medio sujeto) de aquel país de mamíferos incompletos, solo existan habitantes completos, pero claramente malvados. Su única criada es "una mujer muy desgreñada" que chilla y a la que el rey también grita "condenada mujer" y sus animales reciben el calificativo de "malos": gallinas malas, ovejas malas. Los otros elementos, domésticos y realistas, como son el granero y el horno, permiten al lectorado infantil vislumbrar el final previsible y necesario. El río, además, se revela como el adyuvante final y el que le anima a aprovecharse de la situación, no siendo esto aceptado por el medio pollito.

El desenlace, feliz, de comportamiento intachable y generoso por parte del pollito, se desvía de una lectura psicoanalista para ofrecer un orden adecuado del sistema social, que calma al niño y le proporciona la protección y estabilidad que el adulto quiere hacer ver.

\section{Conclusiones}

En definitiva y para concluir este trabajo, se puede ofrecer un cuadro que recopila la información sobre las otras versiones del cuento mencionadas. Contempla analogías y diferencias de todos los textos que constituyen versión de autor en relación con algunos caracteres fundamentales: procedencia de la recogida, personaje oponente al medio pollo, rasgos caracteriales del medio pollo, presencia de lo escatológico y final.

\begin{tabular}{|l|l|l|l|l|l|l|}
\hline $\begin{array}{l}\text { Autor/-a } \\
\text { Recopilador } \\
\text { a }\end{array}$ & $\begin{array}{l}\text { Fernán } \\
\text {-Caballero }\end{array}$ & $\begin{array}{l}\text { Aurelio } \\
\text { M. Espi- } \\
\text { nosa }\end{array}$ & $\begin{array}{l}\text { Arcadio } \\
\text { Larrea }\end{array}$ & $\begin{array}{l}\text { Antonio Ro- } \\
\text { dríguez Al- } \\
\text { modóvar }\end{array}$ & $\begin{array}{l}\text { Rosario } \\
\text { Ferré }\end{array}$ & $\begin{array}{l}\text { Rafael Ji- } \\
\text { jena Sán- } \\
\text { chez }\end{array}$ \\
\hline
\end{tabular}




\begin{tabular}{|c|c|c|c|c|c|c|}
\hline $\begin{array}{l}\text { Obra bi- } \\
\text { bliográfica }\end{array}$ & $\begin{array}{l}\text { La Gaviota } \\
\text { (1849) }\end{array}$ & $\begin{array}{l}\text { Cuentos } \\
\text { populares } \\
\text { (1923, } \\
\text { I } 946)\end{array}$ & $\begin{array}{l}\text { Cuentos } \\
\text { de Aragón } \\
\text { (1947) }\end{array}$ & $\begin{array}{l}\text { Cuentos de la } \\
\text { media lunita } \\
\text { (1985) }\end{array}$ & & \\
\hline $\begin{array}{l}\text { Recogida } \\
\text { oral }\end{array}$ & $\begin{array}{l}\text { Versión } \\
\text { culta y } \\
\text { diferente }\end{array}$ & Cuenca & $\begin{array}{l}\text { Origen } \\
\text { aragonés }\end{array}$ & Sin datos & $\begin{array}{l}\text { Puerto Ri- } \\
\text { co }\end{array}$ & Argentina \\
\hline $\begin{array}{l}\text { Personaje } \\
\text { oponente } \\
\text { al medio } \\
\text { pollo }\end{array}$ & $\begin{array}{l}\text { Todos: } \\
\text { agua, } \\
\text { viento, } \\
\text { cocineros }\end{array}$ & Molinero & Molinero & $\begin{array}{l}\text { Rey e hijo de } \\
\text { rey }\end{array}$ & El rey & $\begin{array}{l}\text { Campesino } \\
\text { rico }\end{array}$ \\
\hline $\begin{array}{l}\text { Rasgos ca- } \\
\text { racteriales } \\
\text { del medio } \\
\text { pollo }\end{array}$ & $\begin{array}{l}\text { Pollito } \\
\text { soberbio, } \\
\text { desprecia- } \\
\text { tivo y con } \\
\text { taras físicas }\end{array}$ & $\begin{array}{l}\text { Procedencia } \\
\text { inicial muy } \\
\text { pobre. Per- } \\
\text { sonaje } \\
\text { plano }\end{array}$ & $\begin{array}{ll}\text { In } & \text { me- } \\
\text { dia } & \text { res. } \\
\text { Personaje } \\
\text { plano }\end{array}$ & $\begin{array}{l}\text { Procedencia } \\
\text { inicial muy } \\
\text { pobre. Polli- } \\
\text { to astuto y } \\
\text { generoso }\end{array}$ & $\begin{array}{l}\text { In media } \\
\text { res. Pollito } \\
\text { generoso }\end{array}$ & $\begin{array}{l}\text { Astuto } y \\
\text { generoso }\end{array}$ \\
\hline $\begin{array}{l}\text { Presencia } \\
\text { de lo esca- } \\
\text { tológico }\end{array}$ & Ausente & Clara & $\begin{array}{l}\text { Clara, muy } \\
\text { popular }\end{array}$ & $\begin{array}{l}\text { Clara, equili- } \\
\text { brio entre lo } \\
\text { popular y lo } \\
\text { culto }\end{array}$ & $\begin{array}{l}\text { Clara, } \\
\text { equilibrio } \\
\text { entre lo } \\
\text { popular y } \\
\text { lo culto }\end{array}$ & $\begin{array}{l}\text { Clara, muy } \\
\text { popular }\end{array}$ \\
\hline $\begin{array}{l}\text { Obra bi- } \\
\text { bliográfica }\end{array}$ & $\begin{array}{l}\text { La Gaviota } \\
\text { (1 849) }\end{array}$ & $\begin{array}{l}\text { Cuentos } \\
\text { populares } \\
\text { (1923, } \\
\text { I946) }\end{array}$ & $\begin{array}{l}\text { Cuentos } \\
\text { de Aragón } \\
\text { (1947) }\end{array}$ & $\begin{array}{l}\text { Cuentos de la } \\
\text { media lunita } \\
\text { (1985) }\end{array}$ & & \\
\hline
\end{tabular}

Si analizamos el cuento de El medio pollito de Carmen Laforet según estos parámetros, podemos ver que el comienzo se da in media res, sin tensiones sociales entre el pueblo y el poder. Existe una idea clara de los medios sujetos desde el inicio, abundando en el sinsentido folclórico e infantil, ya que uno de sus rasgos populares más interesantes es la reiteración, como cuento acumulativo con adyuvantes medio sujetos, siempre con un elemento escatológico claro, leído a la luz de la teoría lacaniana. El desarrollo psicosexual y la pulsión anal resalta la inconsistencia en los medios sujetos, frágiles al lado del medio pollito, resolutivo y luchador. En esta cuestión de los personajes, se ve una evidente oposición entre la jerarquía 
injusta y el abuso de poder simbolizados en el rey, ante el cual el medio pollito presenta su lado bueno. Sin embargo, el desenlace es feliz, moral, ligeramente anticlimático y no popular, lo que no resta el mérito e interés de esta nueva versión de este cuento secular e intemporal, que incluye a Laforet en la nómina de escritores de LIJ.

\section{BIBLIOGRAFía:}

Bettelheim, Bruno (i 978), Psicoanálisis de los cuentos de hadas, Barcelona: Crítica-Grijalbo.

Cervera Borràs, Juan (1986), La literatura infantil en la educación básica, Madrid: Cincel.

Chevalier, Maxime-Camarena Laucirica, Julio (1995), Catálogo tipológico del cuento folklórico español: cuentos maravillosos, Madrid: Gredos (Biblioteca Románica Hispánica, IV, Textos, 24).

Chevalier, Maxime-Camarena Laucirica, Julio (i 995), Catálogo tipológico del cuento folklórico español: cuentos de animales, Madrid: Gredos (Biblioteca Románica Hispánica, IV, Textos, 26).

Coutinho Jorge, Marco António (20 i I), "Las cuatro dimensiones del despertar", Afecttio Societatis, Vol. 8, Número is, s. p.

Del Bosque, Carmen (1 998), La magia de los números, Barcelona: De Vecchi.

Díaz Viana, Luís- Asensio Llamas, Susana (2009), "Introducción” en Aurelio M. Espinosa Cuentos populares recogidos de la tradición oral de España, Madrid: CSIC.

Ferré, Rosario (1996), El medio pollito, s. l.: Alfaguara.

García de Enterría, Paloma (1995) (coord.), Anthropos: Boletín de información y documentación. Literatura popular: conceptos, argumentos y temas, $\mathrm{n}^{\circ} \mathrm{i} 66-\mathrm{i} 67$.

Guerrero Guadarrama, Laura (2013), Posmodernidad en la Literatura Infantil y Juvenil. México: Universidad Iberoamericana.

Hürlimann, Bettina (1 968), Tres siglos de literatura infantil europea, Barcelona: Juventud.

Jijena SÁnchez, Rafael (2003) El medio pollo. Argentina, sl: Editorial el Cardo. Disponible en http://www.biblioteca.org.ar/libros/804I.pdf

Johnson, Roberta (1979), Carmen Laforet, Boston: Twayne Publisher, I 979.

Johnson, Roberta (2O I 2), "El origen de El medio pollito", Palencia: Cálamo, pp. 4I-69.

LACAN, Jacques (2008), El seminario de Jacques Lacan. Libro I7. El reverso del psicoanálisis, I969-1970, Barcelona: Paidós.

LAforet, Carmen (2O 2), El medio pollito, Palencia: Cálamo.

Larrea Palacín, Arcadio de (200o), "Cuentos de Aragón", Temas de antropología aragonesa, No IO, pp. 27-54. ( ( ${ }^{\mathrm{a}}$ ed. I 947$)$.

Lorenzo VÉlez, A. (I98I), "Simbología del número en el folklore y en la canción tradicional", Revista de Folklore, 3, pp. 27-33.

López TAmés, Román (i 990), "Del cuento oral a la narrativa infantil de autor" en Pedro Cerrillo y Jaime García Padrino (coords.), Literatura infantil, Cuenca: Universidad de Castilla-La Mancha, pp. 2 I-37.

Moya Guijarro, A. Jesús.-Albentonsa Hernández, José I. (2007), "Estructura y características lingüísticas de las narraciones infantiles: cuestiones de género y registro" en Pedro C. Cerrillo y Santiago Yubero (coords.), La formación de mediadores para la promoción de la lectura, Cuenca: UCLM-SM, pp. 23 I-250.

Morote, Pascuala (2002), "El cuento de tradición oral y el cuento literario: de la narración a la lectura" en Antonio Mendoza Fillola (coord..), La seducción de la Lectura en edades tempranas, Madrid: Ministerio de Educación, Cultura y Deporte, “col. Aulas de verano”, pp. I 59- I 97.

Navarrete, Micaela (coord.) (200o) Una palomita en mi palomar. Cuentos y relatos campesinos de Chile, s. 1.: FUCOA/BIBAM/Ocho Libros Editores. 
Palomo Vázquez, María del Pilar (1958), “Carmen Laforet y su mundo novelesco”, Monteagudo: Revista de literatura española, hispanoamericana y teoría de la literatura, $\mathrm{n}^{\circ}$ 22, pp. 7-1 3 .

Pelegrín, Ana (i 984), La aventura de oir, Madrid: Anaya, 2004. 2. ${ }^{2}$ ed. corregida y ampliada.

Pelegrín, Ana (1986) Cada cual atienda su juego: de tradición oral y literatura, Madrid: Cincel.

Pelegrín, Ana (1993) "El juego tradicional en la literatura y el arte" en Antonio Rodríguez Almodóvar, Pedro C. Cerrillo, Jaime García Padrino (coords.), La literatura infantil de tradición popular, [Cuenca]: Universidad de Castilla-La Mancha, pp. 45-54.

Pisanty, Valentina (1995), Cómo se lee un cuento popular, Barcelona: Paidós.

Propp, Vladimir (1977), Morfología del cuento. Madrid: Fundamentos.

Pulfer, Darío (2016) Aproximación bio-bibliográfica a Rafael Jijena Sánchez. Buenos Aires: Peronlibros. Disponible en http://www.peronlibros.com.ar/sites/default/files/pdfs/aprox_a rafael jijena_sanchez.pdf .

Redondo, Agustín (2007), Revisitando las culturas del Siglo de Oro. Mentalidades, tradiciones culturales, creaciones paraliterarias y literarias, Salamanca: Universidad de Salamanca.

Ripoll, Blanca (20I6), "Carmen Laforet y el premio Menorca: geografía, novela y premios literarios”, Castilla. Estudios de Literatura, 7, pp. I69- I92.

Rodríguez Almodóvar, Antonio (1993), "Los arquetipos del cuento popular”, en Jaime García Padrino- Pedro C. Cerrillo, Literatura infantil de tradición popular, Cuenca: UCLM, pp. 9-22.

Rodríguez Almodóvar, Antonio (2003), Guía de lectura de los cuentos de La Media Lunita (Una colección de múltiples lecturas), Sevilla: Algaida.

Rodríguez Almodóvar, Antonio (2009), "Introducción" en Cuentos al amor de la lumbre 2 (edición conmemorativa 25 años), Madrid: Alianza Editorial, pp. 3-I 5.

Rojas Navarro, Sebastián (s. d.), El cuento de hadas entre simbolización y simbólica: Lecturas a partir de la relación entre psicoanálisis y literatura, Santiago de Chile: Universidad Diego Portales. Encontrado en https://www.academia.edu/I773975/El_cuento_de_hadas_entre_

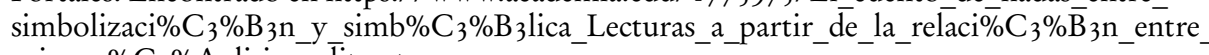
psicoan $\% \mathrm{C}_{3} \% \mathrm{~A}_{\text {I }}$ lisis_y_literatura.

recibido: marzo de 2019

aceptado: septiembre de 2019 